\title{
Технологічні аспекти забезпечення якості деталей при пневмоударному штампуванні вирубуванням-пробиванням
}

\author{
${ }^{1}$ ДВНЗ «Приазовський державний технічний університет» \\ ${ }^{2}$ Національний університет «Полтавська політехніка імені \\ Юрія Кондратюка»
}

\begin{abstract}
Робота присвячена встановленню технологічних можливостей та особливостей процесів вирубування-пробивання тонколистових деталей еластичним середовищем пневмоударного штампування з урахуванням показників їх якості і точності, а також запропоновані ефективні шляхи їх покращення.

Одним з перспективних методів для отримання високоточних деталей, включно зі складним профрілем $\epsilon$ метод формоутворення оснований на технології і обладнанні пневмоударного штампування еластичним середовищем на установках ТА-1324. Перевагами цього методу є екологічна чистота, безпека експлуатації, широкі технологічні можливості, мобільність і універсальність, низькі трудові та енергетичні затрати. На цих установках доцільно виконувати формотворчі операції розділення (вирубуванняпробивання) та неглибокого формування як окремої операції, так і сумісно з вирубуванням-пробиванням. Як заготовки для дослідження застосовувався листовий матеріал марок: сталь 08кп, алюмінієвий сплав АМг-М, сталь 12Х18Н10Т. Товщина матеріалу змінювалася в діапазоні: від 0,5 до 2,5 мм. Матриці і копір-пуансони були виготовлені зі сталі У8А з наступним термічним обробленням до твердості HRC 56-62. Аналіз проведених експериментальних досліджень процесів пробивання-вирубування дозволяє зробити висновок, що зі зростанням кількості відштампованих деталей відбувається збільшення відхилень розмірів від їх номінальних значень. Це збільшення пов'язане зі зношуванням робочих елементів (копір-пуансонів і матриць). При цьому розміри копірпуансонів зменшуються, а розміри матриць збільшуються. Абсолютні величини відхилень не залежать від виду операцій, їх величини як при вирубуванні, так і при пробиванні практично однакові в кожній з узятих вибірок. Аналогічний характер має процес пневмоударного штампування, в якому використовується бойок зі скошеним торцем. У роботі також запропоновані та апробовані шляхи вдосконалення пневмоударного штампування, що забезпечують вирубування, пробивання деталей з листових мідних, алюмінієвих сплавів товщиною 0,3..3 мм і маловуглецевої сталі товщиною до 3 мм. Шорсткість поверхні зрізання знаходиться у межах $\mathrm{Ra}=0,3 \ldots 0,6$ мкм, а у випадку високоміцних матеріалів товщиною до 2,5 мм шорсткість поверхні зрізання $\mathrm{Ra}=0,6 \ldots 1,0$ мкм залежно від конфігураціі контуру, що вирубається або пробивається.
\end{abstract}

Ключові слова: якість, точність, пневмоударне штампування, вирубування, пробивання, тонкий лист, скошений бойок.

\section{Вступ}

Важливим завданням різних галузей машинобудування в сучасних умовах дискретно-нестабільних програм випуску виробів $€$ виготовлення високоякісних виробів з одночасним підвищенням продуктивності праці. Переліченому комплексу вимог відповідає високоенергетичне штампове обладнання, що поєднує гнучкі технологічні модулі і високий рівень автоматизації виробничого процесу з безпечними та дешевими енергоносіями: пневмоударним, електрогідравлічним, магнітоімпульсним штампуванням [1-3].

Одним з перспективних методів для отримання високоточних деталей зі складним профрілем, є метод формоутворення, оснований на технології і облад- 
нанні пневмоударного штампування (ПУШ) еластичним середовищем на установках ТА-1324 з максимальною імпульсною енергією 25 кДж. Перевагами цього методу $є$ екологічна чистота, безпека експлуатації, широкі технологічні можливості, мобільність і універсальність, низькі трудові та енергетичні затрати [4]. Але у літературних джерелах недостатньо відомостей стосовно показників якості і точності деталей, які отримують методом ПУШ, а також не повною мірою висвітлені технологічні особливості і можливості цього методу [5-10].

Мета роботи - встановити технологічні особливості і можливостей процесів вирубування-пробивання тонколистових деталей ПУШ з урахуванням показників їх якості і точності, а також запропонувати ефективні шляхи їх покращення.

\section{Основний матеріал}

На установках ТА-1324 еластичним середовищем доцільно виконувати формотворчі операції розділення (вирубування-пробивання) та неглибокого фрормування як окремої операції, так і сумісно з вирубуванням-пробиванням.

Як заготовки для дослідження застосовувався листовий матеріал марок: сталь 08кп, алюмінієвий сплав АМг-М, сталь 12Х18Н10Т. Товщина матеріалу змінювалася в діапазоні від 0,5 до 2,5 мм.

Розміри відштампованих деталей вимірювалися на інструментальному мікроскопі УІМ-21ПК, шорсткість поверхні зрізання визначалася на блискучому пояску і на поверхні сколювання за допомогою мікроскопа MIC-11 і профріломера-профрілографа моделі 252, величина задирок - мікрометром і оптиметром, що забезпечило при усереднені значень вибірки досягти точності вимірювань 1 мкм, відхилення від площини - за допомогою індикаторів на повіркових плитах.

Матриці і копір-пуансони були виготовлені зі сталі У8А з наступним термообробленям до твердості HRC 56-62.

Аналіз проведених експериментальних досліджень процесів пробиваннявирубування дозволяє зробити висновок, що зі зростанням кількості відштампованих деталей відбувається збільшення відхилень розмірів від їх номінальних значень. Це збільшення пов'язане зі зношуванням робочих елементів (копірпуансонів і матриць). При цьому розміри копір-пуансонів зменшуються, а розміри матриць збільшуються. Абсолютні величини відхилень не залежать від виду операцій: ці величини як при вирубуванні так і при пробиванні, практично однакові в кожній з узятих вибірок. Аналогічний характер має процес ПУШ, в якому використовується бойок зі скошеним торцем.

Необхідно зазначити, що процес ПУШ при виконанні роздільних операцій принципово відрізняється від виготовлення деталей в спеціальних штампах; при цьому відхилення розмірів при вирубуванні збільшується, а при пробиванні отворів - зменшується як за спрямованістю, так і за величиною. При виконанні пробивних операцій в спеціальних штампах відхилення розмірів на $20 . . .30$ \% більше ніж при вирубуванні.

Дослідження геометрії поверхні поділу пробитих отворів, виконані з використанням макрошліфрів, показали, що поверхня поділу має дві чітко окреслені області.

3 боку середовища, що деформує (поліуретану), в пробитих отворах спостерігається пластично деформована ділянка (рис. 1). У діаметральному перерізі ця ділянка має криволінійну форму. 3 боку матриці спостерігається конічна або циліндрична поверхня руйнування (ділянка руйнування).

Ділянка руйнування має шорстку поверхню, тому що утворюється внаслі- 
док тріщин при сколюванні, що зароджуються біля різальної кромки матриці. Висота мікронерівностей залежить від величини зернистості структури матеріалу і знаходиться в межах від 20 до 80 мкм.

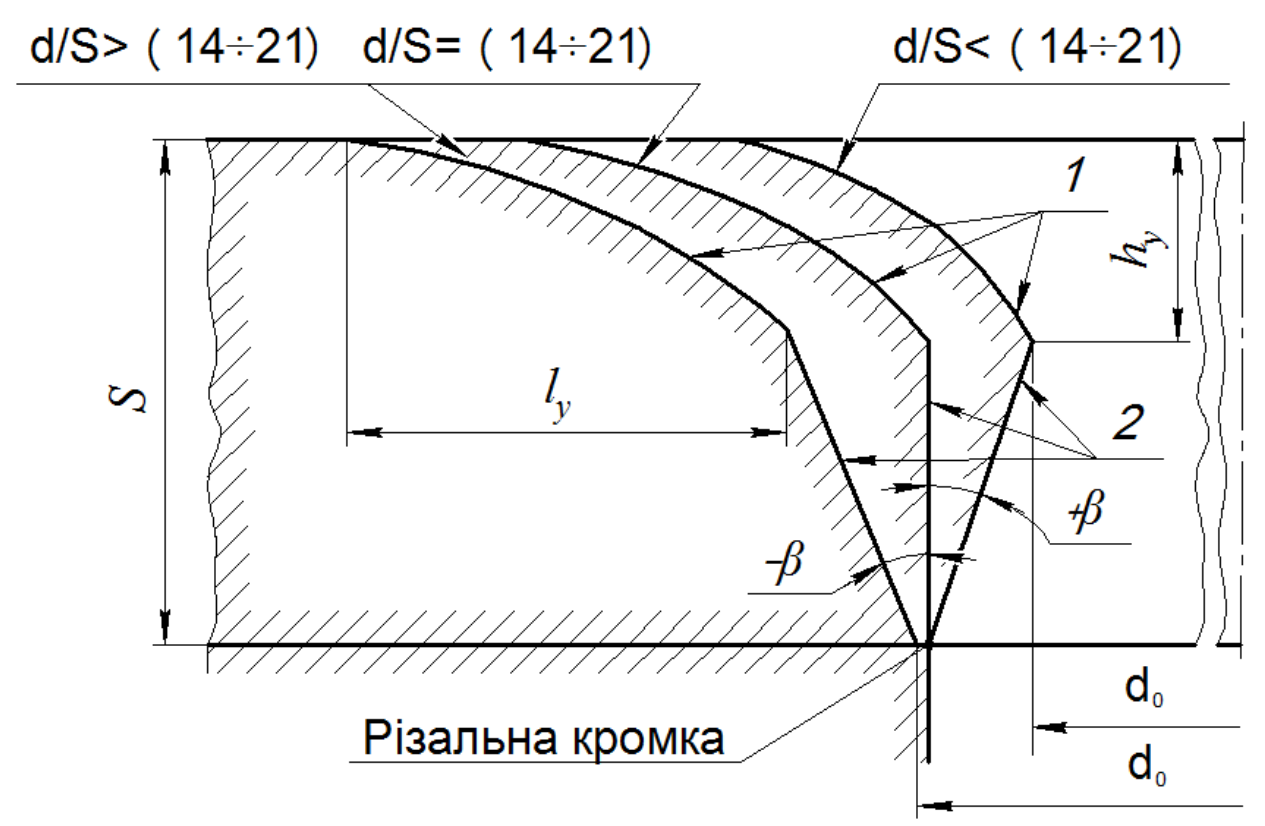

Рис. 1. Форма поверхні поділу в деталі при пробиванні ПУШ отворів залежно від відносного діаметра: 1 - поверхня пластично деформованого матеріалу; 2 поверхня руйнування (сходу);

При товщині 1,0..1,5 мм шорсткість поверхні блискучого пояска перебувала в межах 3,0...7,9 мкм; при товщині 2,0...3,0 мм в межах 3,2..8,4 мкм. Отже шорсткість поверхні зрізання практично не залежить як від товщини матеріалу, так і від кількості відштампованих деталей. Під час штампування відбувається лише поліпшення якості поверхні зрізання внаслідок її згладжування і збільшення (блискучий поясок).

Інші параметри точності, такі як площинність, відхилення від паралельності в процесі ПУШ не зазнають значних змін. Кут сколювання знаходиться в межах 3...5 , а прогин деталі 0,01...0,04 мм.

У перетині пластично деформованої поверхні металу з поверхнею руйнування спостерігається найбільша шорсткість поверхні поділу. Це пояснюється тим, що зона утворена розривом шарів металу, які контактують з деформівним середовищем при виході тріщин сколювання на поверхню заготовки.

У перетині пластично деформованої поверхні металу з поверхнею руйнування спостерігається найбільша шорсткість поверхні поділу. Це пояснюється тим, що ця зона утворена шляхом розриву шарів металу, які контактують з середовищем, що деформує, при виході тріщин сколювання на поверхню заготовки.

За аналогією з пробиванням отворів в інструментальних штампах геометрія поверхні поділу круглих пробитих отворів в діаметральному перетині при ПУШ оцінюється такими показниками: $h_{y}$ - вертикальне утягування; $l_{y}$ - горизонтальне утягування; $\beta$ - кут нахилу поверхні руйнування; 
$\left(\Delta_{o}=d_{0}-d_{M}\right)$ - показник точності розмірів як різниця між діаметрами отворів в деталі $d_{0}$ і матриці $d_{M}$.

При пробиванні круглих отворів в заготовках з металевих матеріалів які мають $\sigma_{B}=200 . .600 \mathrm{MПа,} \mathrm{форма} \mathrm{поверхні} \mathrm{поділу} \mathrm{залежить} \mathrm{від} \mathrm{відношення}$ $d / S$. При $d / S<14 . .21$ кут $\beta \in$ від'ємним, а при $d / S>14 . .21$ - додатній. Форма поверхні руйнування близька до циліндричної при $d / S=14 . .21$. У широкому діапазоні вертикальні й горизонтальні утягування змінюються в порівняно невеликих межах $l_{y}=(0,8 \ldots 1,3) S, h_{y}=(0,4-0,5) S$.

Вплив $d / S$ на форму поверхні руйнування визначається тим, що зі зміною $d / S$ відбувається зміна опору деформації відходів і їх напруженодесормованого стану в зоні ріжузальної кромки штампа. При $d / S>14 . .21$ деформований стан поблизу поверхні руйнування - зсув, суміжний з розтягуванням. Напрямок тріщин сколювання в значній мірі залежить від напружень розтягу, що діють з боку відходу. При $d / S<14 . .21$ деформований стан - зсув, суміжний із стисненням. У цьому діапазоні форма поверхні поділу визначається співвідношенням згинальних моментів, напружень стиску і ріжучих сил. Деформований стан поблизу поверхні руйнування близький до зсуву тільки у вузькому діапазоні $d / S=14 . .21$. У цьому діапазоні поверхня руйнування $є$ близькою до циліндричної форми поверхні поділу, що отримується при пробиванні отворів в інструментальних штампах з двома жорсткими фоормотворними елементами (пуансоном і матрицею).

Форма поверхні поділу залежить від фрізико-механічних властивостей матеріалу, що пробивається. 3 підвищенням пластичності матеріалу заготовок збільшуються значення $h_{y}$ і $l_{y}$. Наочно вплив пружних властивостей матеріалу заготовки на форму поверхні поділу видно за формою пробитих отворів у швидкорізальній сталі Р18 та у свинцю - в матеріалах, що мають діаметрально протилежні властивості за показниками пластичності. При пробиванні Р18 коефріцієнти $h_{y}$ і $l_{y}$ близькі до нуля, а при пробиванні свинцю $l_{y}=2 \delta$, а $h_{y} \in$ близьким до одиниці.

При вирубуванні зовнішнього контуру деталей з опорними рамками форма поверхні поділу визначається відносним зазором $(\delta / S)$ між опорною рамкою і різальною кромкою матриці, фрізико-механічними властивостями матеріалу заготовки і розмірами деталей, що вирубуються (рис. 2). Найбільш значущими $є$ перший і другий фрактори. Залежність фрорми поверхні поділу при вирубуванні круглих деталей від $\delta / S$ і фрізико-механічних властивостей матеріалу аналогічна залежності форми поверхні поділу при пробиванні круглих отворів від $d / S$. Зі збільшенням $\delta / S$ також змінюється напружено-деформований стан поблизу поверхні руйнування і форма поверхні поділу.

При $\delta / S<8 \ldots 15$ деформований стан - зсув, суміжний із стисненням, кут $\beta$ - від'ємний, при $\delta / S>8 \ldots 15$ деформований стан - зсув, суміжний з розтягуванням, кут $\beta$ - додатній. Форма поверхні поділу близька до циліндричної при $\delta / S=8 \ldots 15$.

Розміри пробитих отворів відрізняються від розмірів отворів матриць у зв'язку з наявністю систематичних і випадкових похибок. Систематичні похибки найбільш істотно залежать від $d / S$ і фізико-механічних властивостей матеріалу заготовки. 


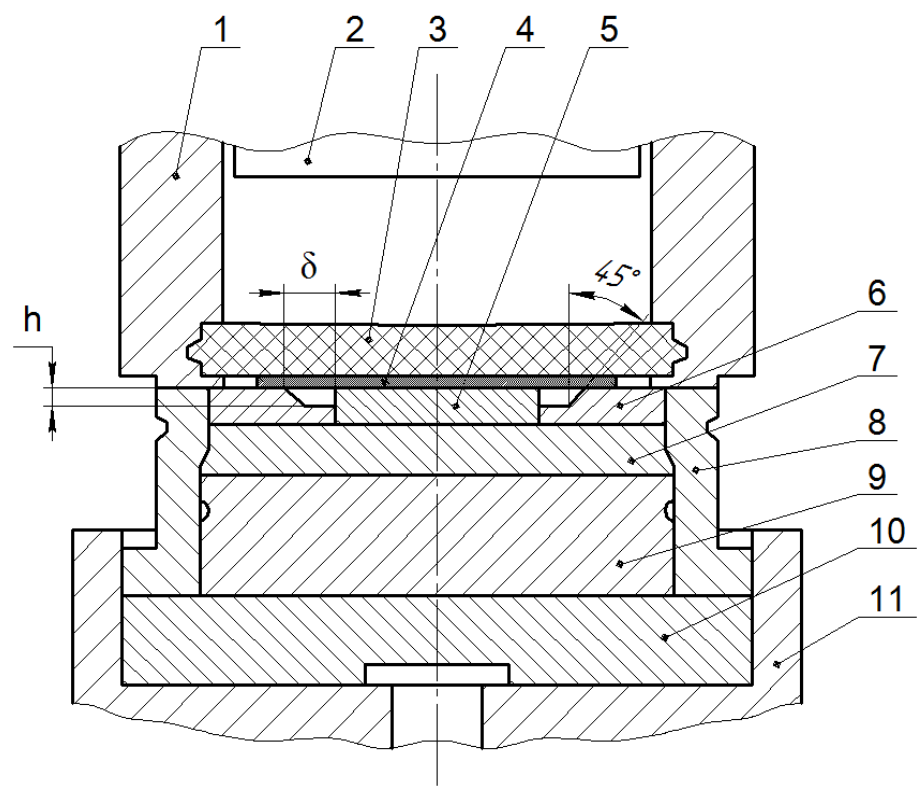

Рис. 2 - Технологічна схема вирубування поліуретаном із застосуванням матриць і опорних рамок: 1 - ствол машини; 2 - бойок, 3 - діафрагма поліуретанова; 4 - заготовка; 5 - матриця; 6 - опорна рамка; 7 - диск;

8- обойма; 9,10 - плита; 11 - контейнер

На рисунку 3 показана залежність $d_{0}-d_{M}=\Delta b$, з якої випливає, що зі збільшенням $d / S$ знак $\Delta_{0}$ змінюється з мінуса на плюс. Це означає, що розміри пробитих отворів при $d / S<14 . .21$ менше розмірів отворів матриці, а при $d / S>14 . .21$ - більше.

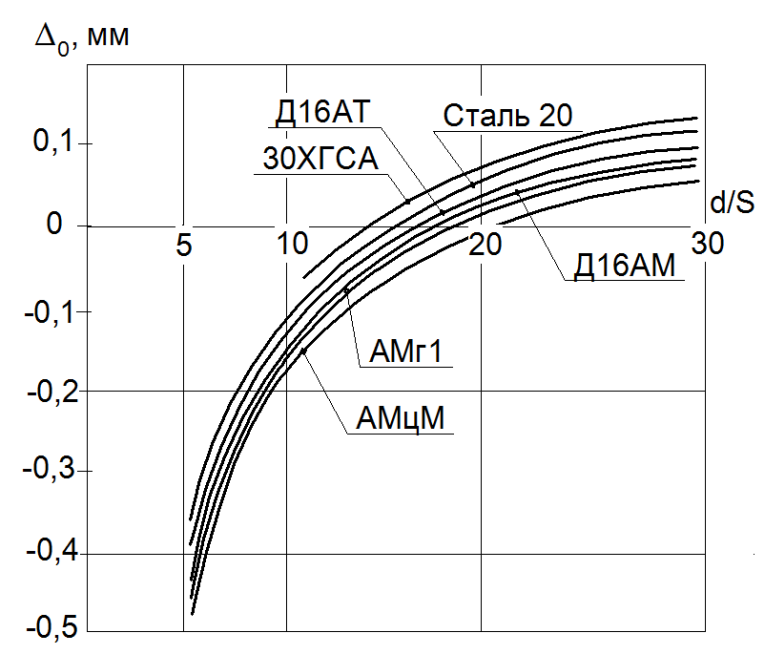

a

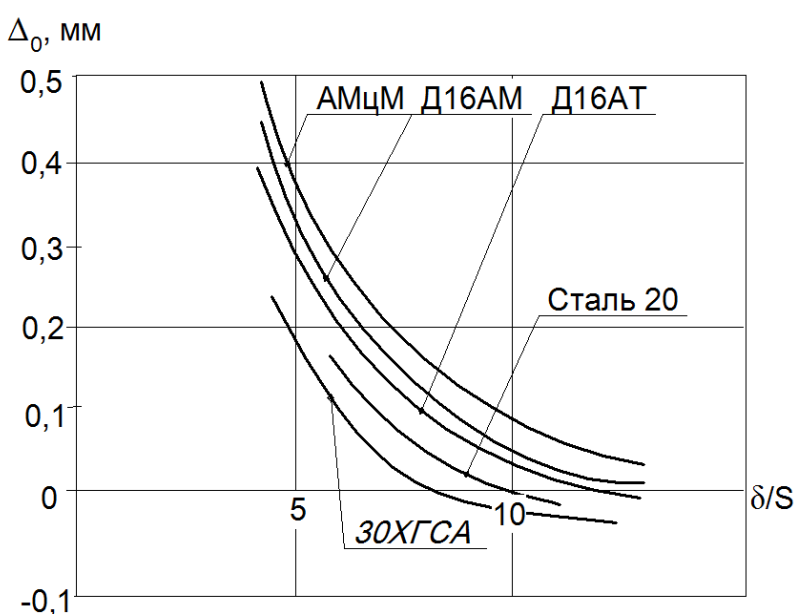

6

Рис. 3. Залежності систематичних похибок розмірів пробитих отворів і зовнішнього контуру деталей: а - при пробиванні отворів; б - при вирубуванні [11]

Характер залежностей $\Delta_{0}$ від $d / S$ в цих двох інтервалах $є$ різним. При малих значеннях $d / S<14 . .21$ і пробиванні круглих отворів на порядок більше, ніж при $d / S>14 . .21$. 
Зазначені закономірності $\triangle_{0}$ при $d / S=14 . .21$ вказують на наявність фрактора, що істотно змінюється при цих значеннях $d / S$. Цим фактором $€$ кут нахилу поверхні руйнування $\beta$, який значною мірою визначає форму поверхні поділу і закономірності зміни $\Delta_{0}$ в широкому діапазоні $d / S$. При від'ємних значеннях $\beta$ значення $\Delta_{0}$ також від'ємне, тому що вимірювання діаметра пробитого отвору проводиться в зоні перетину поверхонь руйнування і пластично деформованої поверхні.

Таким чином, в інтервалі $d / S<14 \ldots 21$ точність пробитих отворів залежить від форми поверхні поділу і визначається процесами пластичного деформування і напрямком тріщин сколювання при відокремленні відходу.

Точність пробитих отворів в інтервалі $d / S>14 . .21$ не залежить від форми поверхні поділу (кут додатний). Розміри пробитих отворів вимірюють в площині заготовки, що контактує з матрицею. Поділ матеріалу по цій площині відбувається на початковій стадії дефрормування відходів до появи тріщин сколювання. Збільшення розмірів пробитих отворів відносно розмірів матриць $є$ наслідком пружних переміщень деталі після відокремлення відходів.

Точність розмірів деталей на зовнішньому контурі залежить від величини відносного зазору $\delta / S$, розмірів деталей, що вирубуються, і фізико-механічних властивостей матеріалу заготовки. Найбільш значущим чинником, що визначає точність деталей, що вирубуються, $€ \delta / S$. У зв'язку з тим, що при $\delta / S<8 \ldots 15$ кут $\beta$ є від'ємним, розміри вирубаних деталей більше відповідних розмірів матриці.

Унаслідок пружних деформацій деталі після відокремлення відходу при $\delta / S>8 \ldots 15$ розміри вирубаних деталей менше розмірів матриць. При вирубуванні зміна форми поверхні поділу і $\Delta$ досягається зміненням величини зазору $\delta$.

Підвищення точності пробивання отворів досягається коригуванням розмірів отворів матриці з метою компенсації систематичної похибки $\Delta_{0}$ (див. рис. 3) і керуванням процесом деформації відходів шляхом установки підпірачів. При пробиванні отворів 3 підпірачем при $d / S>14 . .21$ напружено-деформований стан в зоні поверхні поділу буде залежати від величини відносного зазору між підпірачем та різальною кромкою $\left(\delta_{n} / S\right)$. Зі зменшенням $\delta_{n} / S$ знижуються радіальні напруження розтягу. Установлення підпірачів дозволяє отримати від'ємні і близькі до нуля значення $\Delta_{0}$, змінити форму поверхні поділу.

Точність розмірів деталей, що досягається ПУШ

Таблиця 1

\begin{tabular}{|c|c|c|c|}
\hline \multicolumn{3}{|c|}{ Показники } & Значення \\
\hline \multirow{2}{*}{$\begin{array}{c}\text { Точність ро- } \\
\text { змірів } \\
\text { деталей }\end{array}$} & $\begin{array}{c}\text { При } \mathrm{S}=2 \ldots 3 \text { мм, } \\
\delta / S<8 \ldots 15\end{array}$ & $d / S>14 . .21 ;$ & До 8-12 квалітету \\
\cline { 2 - 4 } & $\begin{array}{c}\text { При } \mathrm{S}<1 \mathrm{mм}, \\
\delta / S<8 \ldots 15\end{array}$ & $d / S<14 . .21 ;$ & До 12-14 квалітету \\
\cline { 2 - 4 } & & $d / S>14 . .21 ;$ & До10-12 квалітету \\
\hline
\end{tabular}


Открытые информационные и компьютерные интегрированные технологии № 87, 2020

Таблиця 2

Граничні розміри деталей та їх конструктивних елементів

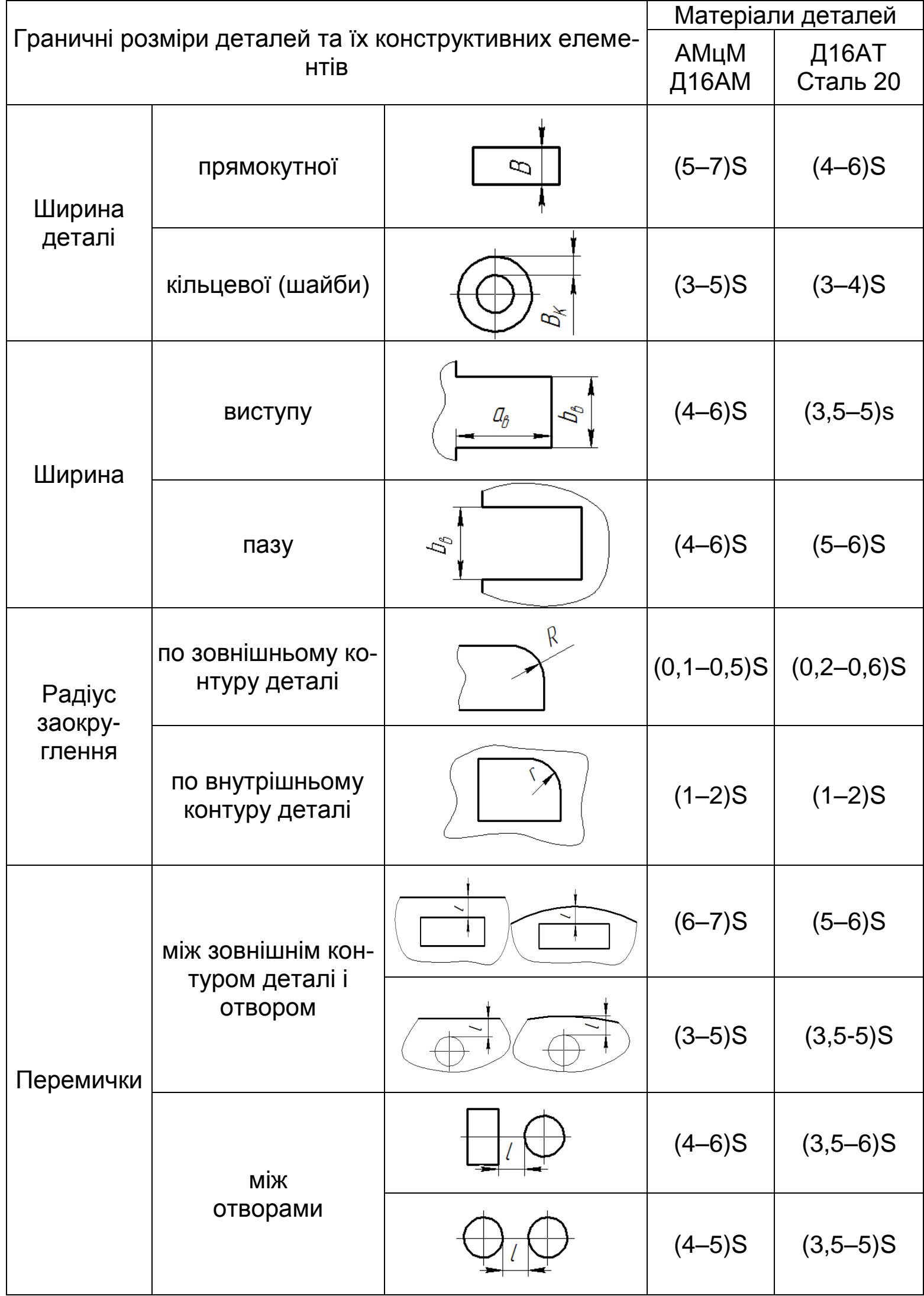


Як видно з таблиць 1 та 2, в яких наведені експериментальні дані про досяжну точність ПУШ різноманітних контурів при вирубуванні та пробиванні, при встановленні номенклатури деталей можна рекомендувати використовувати найпростіші співвідношення між мінімальними розмірами конструктивних елементів деталей і товщиною заготовки S.

Установлено що рекомендована точність розмірів відповідно до наведених даних при вирубуванні на провал залежно від номінального розміру, товщини матеріалу відповідає 7 - 16 квалітету (при товщині матеріалу від $0,1 \ldots 3$ мм і номінальному розмірі до 300 мм) на штампувальному оснащенні нормальної точності, а на оснащенні підвищеної точності - 7-13 квалітету точності; при пробиванні в тих само умовах точність розмірів отворів відповідає 7 - 14 квалітету, а при підвищеній точності виготовлення штампового оснащення - 7 - 9 квалітету точності (табл. 3).

Таблиця 3

Параметри точності пластин при вирубуванні з різноманітних матеріалів

\begin{tabular}{|c|c|c|c|c|c|c|c|c|}
\hline \multirow{2}{*}{ Матеріал } & \multicolumn{5}{|c|}{$\begin{array}{c}\text { Величина сумарної похибки, мм/квалітет, } \\
\text { при інтервалах розмірів }\end{array}$} \\
\cline { 2 - 9 } & $20-60$ & \multicolumn{2}{|c|}{$60-100$} & \multicolumn{2}{c|}{$100-150$} & \multicolumn{2}{c|}{$150-200$} \\
\hline $\begin{array}{c}\text { Сталь 10кп, } \\
\text { Сталь 08кп, } \\
\text { Дюралюміній, } \\
\text { АМг6 }\end{array}$ & $\frac{0,36}{7}$ & $\frac{0,068}{8-9}$ & $\frac{0,06}{8-9}$ & $\frac{0,120}{10}$ & $\frac{0,750}{8-9}$ & $\frac{0,130}{10}$ & $\frac{0,100}{9}$ & $\frac{0,150}{10}$ \\
\hline $\begin{array}{c}\text { Латунь } \\
\text { ЛС59-1-0, } \\
\text { Бронза } \\
\text { БрАЖ9-4 }\end{array}$ & $\frac{0,047}{8-9}$ & $\frac{0,075}{10}$ & $\frac{0,072}{8-9}$ & $\frac{0,118}{10}$ & $\frac{0,088}{8-9}$ & $\frac{0,160}{10}$ & $\frac{0,172}{8-9}$ & $\frac{0,190}{10}$ \\
\hline \begin{tabular}{c} 
Сталь Э12 \\
\hline
\end{tabular} & $\frac{0,100}{10}$ & $\frac{0,132}{11}$ & $\frac{0,142}{10}$ & $\frac{0,200}{11}$ & $\frac{0,177}{8-9}$ & $\frac{0,232}{11}$ & $\frac{0,212}{10}$ & $\frac{0,278}{12-13}$ \\
\hline
\end{tabular}

До критеріїв, що визначають мінімальні розмір деталей і їх конструктивні елементи, належать мінімальні розміри круглих і прямокутних деталей, виступів, пазів, перемичок і радіусів заокруглень тощо (див. табл. 2). Зазначені критерії віднесені до показників якості деталей, тому що при виготовленні деталей і їх конструктивних елементів з розмірами, меншими мінімально допустимих, виникають різні види браку: спотворення фрорми деталей та їх елементів, розриви деталей на перемичках, розривання матеріалу, що штампують в кутах отворів та інші.

Ці види браку виникають в тому випадку, якщо порушується рівновага сил, що запобігають пластичній деформації деталі або ії̈ конструктивного елементу в площині матриці, і зусиль розтягу, що діють з боку відходу. Якщо в процесі вирубування і пробивання ці запобіжні сили, більші за зусилля розтягу, то розміри деталей і їх конструктивних елементів $€$ достатні та брак виключений. 
Таблиця 4

Рекомендовані значення висоти шаблонів для вирубування-пробивання

\begin{tabular}{|c|c|c|c|c|c|c|c|c|c|}
\hline \multirow{2}{*}{ Матеріал } & \multirow{2}{*}{$\delta, \%$} & \multicolumn{8}{|c|}{ Товщина матеріалу, мм } \\
\hline & & 0,1 & 0,3 & 0,5 & 0,8 & 1,0 & 1,2 & 1,5 & 2,0 \\
\hline $\begin{array}{c}\text { Сталі 65Г, 60С2, У8, } \\
\text { У10; бронза, мідь, ла- } \\
\text { тунь Л63Т, алюміній АД, } \\
\text { АМг, АМц, В95 }\end{array}$ & $<12$ & 1,0 & 2,0 & 2,5 & 3,5 & 4,0 & 4,8 & 5,5 & 7,0 \\
\hline $\begin{array}{c}\text { Сталі 20, 30, 45, Ст3, } \\
\text { 2Х13; } \\
\text { латунь Л63ПТ; алюміні- } \\
\text { єві сплави } \\
\text { АМцМ, АМгМ, Д1АМ }\end{array}$ & $15 \ldots 25$ & 1,5 & 2,5 & 3,5 & 4,0 & 5,0 & 6,0 & 6,8 & 8,0 \\
\hline $\begin{array}{l}\text { Сталь 08кп, Х18Н10Т; } \\
\text { мідь М1M, М3М, латунь } \\
\text { Л63М; алюміній А2, А3 }\end{array}$ & $>25$ & 2,0 & 3,0 & 4,0 & 5,0 & 6,0 & 7,0 & 8,0 & 10,0 \\
\hline
\end{tabular}

У таблицях 4 та 5 представлені відповідно визначені експериментально рекомендовані значення висоти шаблонів для вирубування-пробивання та досяжні мінімальні значення геометричних параметрів деталей, що визначають технологічні можливості ПУШ.

Ефективнішими будуть шляхи, що приводять до зменшення стоншування заготовки в зоні вигину до моменту руйнування і зумовлюють доцільне спрямовання тріщини або не одночасне прикладення навантаження по контуру заготовки яка штампується.

Проведені експериментальні дослідження процесу поділення листового металу еластичним середовищем дозволили встановити ефективні шляхи вдосконалення розділових операцій ПУШ, основним з яких $є$ поліпшення геометричної точності поверхні зрізу заготовки. Це реалізується внаслідок локалізації осередку пластичної деформації, керування траєкторією тріщини руйнування, використання еластичного середовища з вищою твердістю (поліуретан СКУ ПФЛ-74).

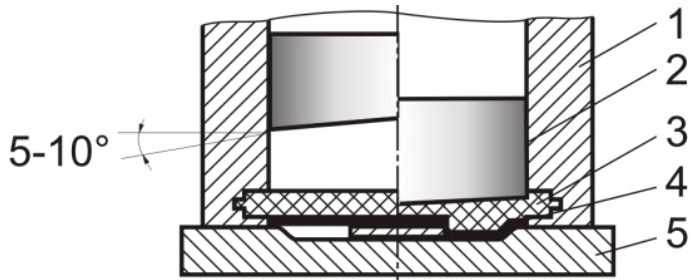

a

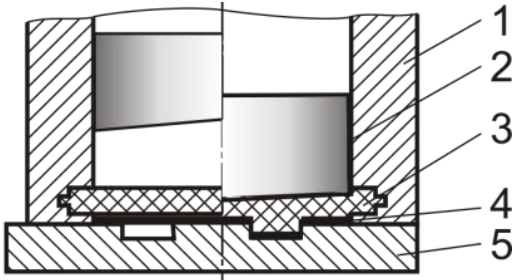

б

Рис. 4. Основні технологічні схеми штампування еластичним середовищем зі скошеним бойком (поліуретаном марок СКУ-7Л, СКУ-ПФЛ):

а - пробивання; б - вирубування, 1 - ствол, 2 - бойок скошений під кутом, 3 - поліуретанова мембрана, 4 - заготовка, 5 - шаблон 
Таблиця 5

Мінімально досяжні значення геометричних параметрів деталей при ПУШ

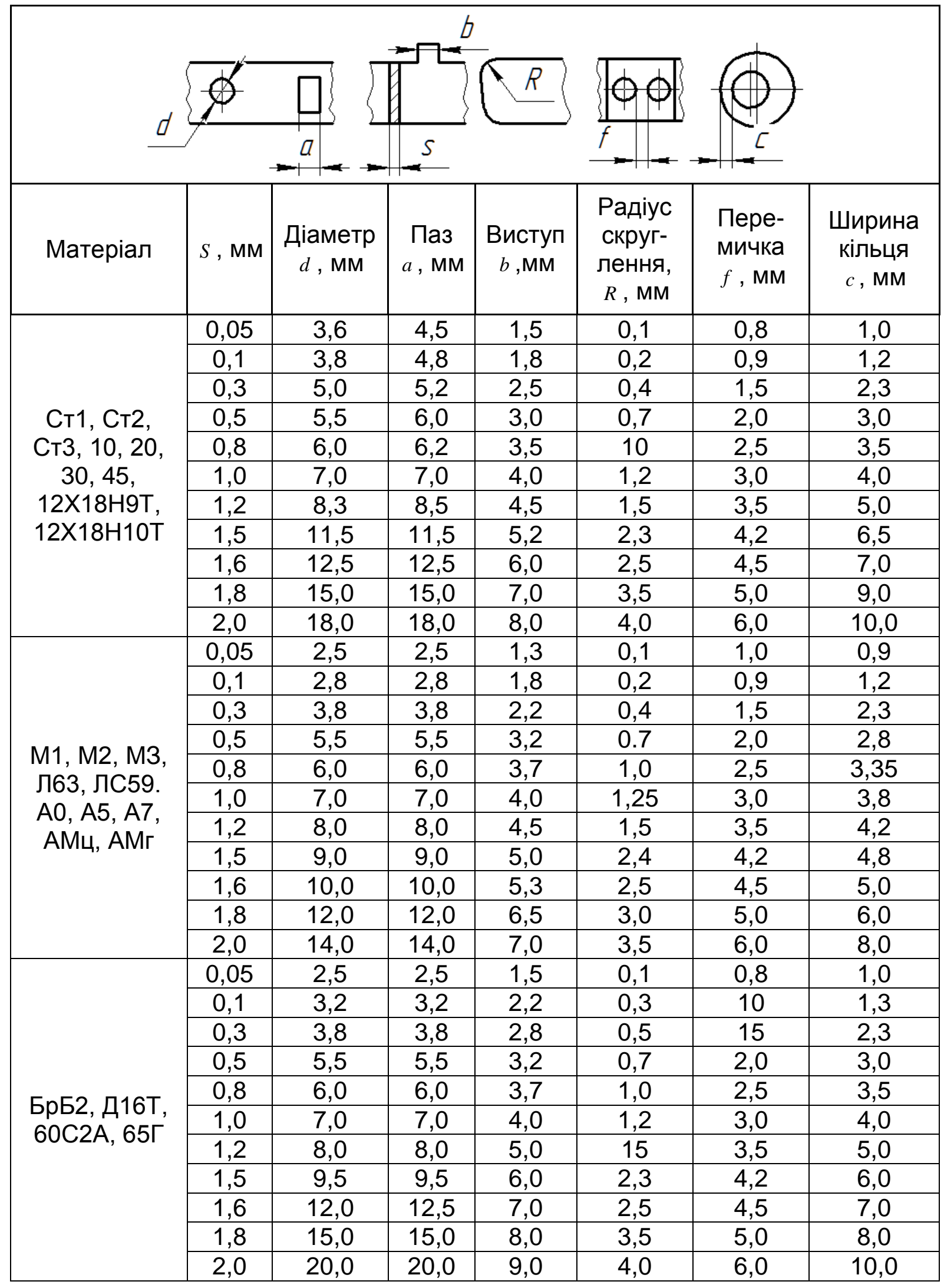


Не вдаючись до ускладнення оснащення, локалізацію осередку пластичної деформації можна забезпечити при послідовному відокремленні припуску ударом по поліуретану скошеного під кутом $5 . . .10^{\circ}$ торця бойка пневмоударної установки ТА-1324 (рис. 4). У цьому випадку розділення матеріалу заготовки відбувається послідовно за периметром розділення. починаючи з місця де є найбільший тиск і найбільш жорстка схема напружено-деформованого стану.

Локалізація тиску забезпечує поділ припуску спочатку лише в одній зоні контуру деталі. При цьому за рахунок меншого кута вигину припуску до моменту утворення тріщини знижується потоншування заготовки в зоні поділу.

\section{Висновки}

Встановлені технологічні можливості і особливості процесів вирубуванняпробивання з урахуванням показників якості і точності тонколистових деталей ПУШ на установці ТА-1324 з максимальною імпульсною енергією 25 кДж: залежності систематичних похибок розмірів при вирубуванні-пробиванні; параметри точності пластин різного розміру при вирубуванні з різноманітних матеріалів; мінімально досяжні значення геометричних параметрів деталей та рекомендовані значення висоти шаблонів для їх вирубування-пробивання. Також запропоновані і апробовані шляхи з вдосконалення ПУШ, що забезпечують вирубування, пробивання деталей з листових мідних, алюмінієвих сплавів товщиною 0,3..3 мм і маловуглецевої сталі товщиною до 3 мм. Досяжна шорсткість поверхні зрізання на деталях $R_{a}$ становить 0,3...0,6 мкм, а у випадку високоміцних матеріалів товщиною до 2,5 мм шорсткість поверхні зрізання 0,6...1,0 мкм залежно від конфрігурації контуру, що вирубається або пробивається.

\section{Список літератури}

1. Петраковский, В. С. Оценка штампуемости материалов при гидроударной вытяжке листового металла / В. С. Петраковский // Импульсные методы обработки металлов. - Минск: Наука и техника. - 1977. - С. 123 - 131.

2. Наумович, Т. М. Исследование и разработка методик расчета технологических процессов обработки материалов на гидроударных установках: дис. ... канд. техн. наук / Наумович Тамара Митрофановна. - Минск, 1981. 135 с.

3. Комаров, А.Д. Штамповка трубчатых деталей эластичной средой на пневмогидравлической установке / А. Д. Комаров, В. К. Моисеев, Ф.В.Киров // Кузнечно-штамповочное производство. - 1976. - №2. - С. 31 - 32.

4. Импульсные методы листовой штамповки / Н.Д. Жолткевич, А. Я. Мовшович, Е.А. Фролов, В.П. Усанин // Вопросы оборонной техники. 1991. - Сер. ІІ/ Вып. 6. - С. 3-21.

5. Фролов, Е.А. Оценка качественных показателей деталей из листа при операциях пробивки - вырубки эластичной средой на пневмоударном оборудовании / Е. А. Фролов, И.В.Манаенков, Т.В.Дякова // Збірник наукових праць УДАЗТ. - Харків: Українська державна академія залізничного транспорту. 2008. - Вип. 99. - С. 250-256.

6. Фролов, Е.А. Пути повышения качества технологической системы пневмоударной штамповки листовых деталей / Е. А. Фролов, С. С. Тимофеев, Т. В. Дякова. // Удосконалення будівельних колій та перевантажувальних машин: зб. наук. пр. Укр. держ. академії залізн. трансп. - Вып. 88. - Харків, 2008. C. $166-172$. 
7. Конструирование инструментов для ударной импульсной штамповки. / А.Я. Мовшович, И.В. Манаенков, В.В. Косенков, Ю.М. Свиридов // Високі технології в машинобудуванні: зб.наук. пр. Нац. техн. ун-ту «ХПІ» . - Вип. 2 (17). Харків, 2008. - С. 248-255.

8. Исследование упругой деформации эластичных элементов штамповой оснастки / А.С. Анищенко, В.В. Кухарь, А.Г. Присяжный, В.В. Глазко, С.Г. Ясько // Збірник наукових праць. Серія: Галузеве машинобудування, будівництво. Вип. 1 (46). - ПолтНТУ, 2016. - С. 4 - 13.

9. Definition of the influence of technological and constructive parameters of technical systems on energy-power characteristics of pneumatic-shock forming / E.A. Frolov, Yasko S.G., Kravchenko S. I. // Aerospace technic and technology. 2016. - № 3 (130). - pp. 23 - 29.

10. To the question of manufacturing high-quality perforated detail made of fiberglass by stamping / E. A. Frolov, S. G. Yasko, S. I. Kravchenko, O. H. Nosenko // Открытые информационные и компьютерные интегрированные технологии: сб. науч. тр Нац. аэрокосм. ун-та им.Н. Е. Жуковского "ХАИ", - Вып. № 71. Харьков,- 2016.- С. $93-99$.

11. Фролов Е. А. Научные основы пневмоударной штамповки сложнорельефных тонколистовых деталей. Дисс. ... докт. техн. наук. / Фролов Євгений Андреевич. - Краматорск, 2003. - 370с.

\section{References}

1. Petrakovskii, V.S. Otsenka shtampuemosti materialov pri gidroudarnoi vytyazhke listovogo metalla [Estimation of the stamping of materials in sheet metal shock-proof drawing] / V.S. Petrakovskii // Impul'snye metody obrabotki metallov. Minsk: Nauka i tekhnika. - 1977. - S. $123-131$.

2. Naumovich, T.M. Issledovanie i razrabotka metodik rascheta tekhnologicheskih protsessov obrabotki materialov na gidroudarnykh ustanovkakh [Research and development of methods of calculation of technological processes of processing of materials on hydraulic shock installations] : dis. ... kand. tekhn. nauk / Naumovich Tamara Mitrofanovna. - Minsk, 1981. $135 \mathrm{~s}$.

3. Komarov, A.D. Shtampovka trubchatykh detalei elastichnoi sredoi na pnevmogidravlicheskoi ustanovke [Punching of tubular parts with an elastic medium on a pneumatic hydraulic unit] / A.D. Komarov, V.K. Moiseev, F.V. Kirov // Kuznechno-shtampovochnoe proizvodstvo. - 1976. - №2. - S. 31 - 32.

4. Impul'snye metody listovoi shtampovki [Impulse methods of sheet stamping] / N.D. Zholtkevich, A.Ya. Movshovich, E.A. Frolov, V.P. Usanin // Voprosy oboronnoi tekhniki. - 1991. - Ser. II/ Vyp. 6. - S. 3-21.

5. Frolov, E.A. Otsenka kachestvennykh pokazatelei detalei iz lista pri operatsiyakh probivki - vyrubki elastichnoi sredoi na pnevmoudarnom oborudovanii [Evaluation of the quality indicators of parts from a sheet during punching operations - cutting down with an elastic medium on pneumatic impact equipment] / E.A. Frolov, I.V. Manaenkov, T.V. Dyakova // Zbirny`k naukovy'x pracz' UDAZT. -Xarkiv: Ukrayins`ka derzhavna akademiya zalizny`chnogo transportu. - 2008. - Vy`p. 99. pp. 250-256.

6. Frolov, E.A. Puti povysheniya kachestva tekhnologicheskoi sistemy pnevmoudarnoi shtampovki listovykh detalei [Ways to improve the quality of the technological system of pneumatic impact stamping of sheet parts] / E.A. Frolov, S.S. Timofeev, T.V. Dyakova. // Udoskonalennya budivel'ny’x kolij ta perevantazhu- 
val’ny`x mashy`n: zb. nauk. pr. Ukr. derzh. akademiyi zalizn. transp. - Vy`p. 88. Xarkiv, 2008. - pp. $166-172$.

7. Movshovich, A.Ya. Konstruirovanie instrumentov dlya udarnoi impul'snoi shtampovki [Designing tools for impact punching. High technology in machine science] / A.Ya. Movshovich, I.V. Manaenkov, V.V. Kosenkov, Yu.M. Sviridov // Vy`soki texnologiyi v mashy`nobuduvanni: zb.nauk. pr. Nacz. texn. un-tu «XPI» - Vy`p. 2 (17). - Xarkiv, 2008. - pp. 248-255.

8. Anishchenko, A.S. Issledovanie uprugoi deformatsii elastichnykh elementov shtampovoi osnastki [The study of elastic deformation of elastic elements of die tooling] / A.S. Anishchenko, V.V. Kukhar', A.G. Prisyazhnyi, V.V. Glazko, S.G. Yas'ko // Zbirny`k naukovy`x pracz`. Seriya: Galuzeve mashy`nobuduvannya, budivny`cztvo. Vy`. 1 (46). - PoltNTU, 2016. - pp. 4-13.

9. Frolov, E.A. Definition of the influence of technological and constructive parameters of technical systems on energy-power characteristics of pneumatic-shock forming / E.A. Frolov, Yasko S.G., Kravchenko S. I. // Aerospace technic and technology. - 2016. - № 3 (130). - pp. 23 - 29.

10. Frolov E.A., To the question of manufacturing high-quality perforated detail made of fiberglass by stamping / E.A. Frolov, S.G. Yasko, S.I. Kravchenko, O.H. Nosenko // Otkrytye informatsionnye i komp'yuternye integrirovannye tekhnologii: sb. nauch. tr. - Khar'kov: Nats. aerokosm. un-t "KhAl", 2016. - Vyp. № 71. - pp. $93-99$.

11. Frolov E.A. Nauchnye osnovy pnevmoudarnoi shtampovki slozhnorel'efnykh tonkolistovykh detalei [Scientific principles of pneumatic impact stamping of complex relief small-sheet parts]. Diss. ... dokt. tekhn. nauk. / Evgenii Andreevich Frolov. - Kramatorsk, 2003. - 370 p.

Поступила в редакцию 18.12.2019. Рассмотрена на редколлегии 20.12.2019.

\section{Technological aspects of ensuring quality of parts produced by cutting-punching operation during pneumatic impact stamping}

The paper considers the issues related with technological capabilities and features of the process of cutting-punching of sheet-metal parts with an elastic medium of pneumatic impact stamping, taking into account the indicators of their quality and accuracy, and also suggests effective ways to improve them.

One of the promising methods for producing high-precision parts, including those with a complex profile, is a shaping method based on the technology and equipment of pneumatic shock stamping with an elastic medium on the TA-1324 installations. The advantages of this method are environmental cleanliness, safe operation, wide technological capabilities, mobility and versatility, low labour and energy costs. At these installations it is advisable to perform formative operations of separation (cutting-punching) and shallow shaping both as a separate operation and together with cutting-punching. As a workpiece for the study the sheet material of the following grades was used: steel 08kp, aluminium alloy AMG-M, steel $12 \mathrm{X} 18 \mathrm{H} 10 \mathrm{~T}$. The thickness varied within the range from 0.5 to $2.5 \mathrm{~mm}$. Dies and copier punches were made of U8A steel, followed by heat treatment to a hardness of HRC 56-62. An analysis of the experimental studies of punching-cutting processes allows us to conclude that with an increase in the number of stamped parts, there is an increase in size deviations from their nominal values. This increase is due to the wear of operat- 
ing elements (copier punches and dies). At the same time, the sizes of the copier punches are reduced, and the sizes of the matrices are increased. The absolute values of deviations do not depend on the type of operations; their values, both during cutting and punching, are almost the same in each of the samples taken. The process of pneumatic impact stamping, where a hammer with a bevelled end was used, has a similar character. The paper also proposed and tested ways to improve pneumatic impact stamping, providing cutting, punching of parts from sheet copper, aluminium alloys with a thickness of 0.3 to $3 \mathrm{~mm}$ and mild steel up to $3 \mathrm{~mm}$ thick. The roughness of the cutting surface is in the range $R a=0.3$ to $0.6 \mu \mathrm{m}$, and in the case of high-strength materials up to $2.5 \mathrm{~mm}$ thick, the roughness of the cutting surface is $\mathrm{Ra}=0.6$ to $1.0 \mu \mathrm{m}$, depending on the contour configuration that is cut down or punched.

Key words: quality, accuracy, pneumatic impact stamping, cutting, punching, thin sheet, bevelled hammer.

\section{Сведения об авторах:}

Кухарь Владимир Валентинович - доктор технических наук, професcop, заведующий кафедрой обработки металлов давлением ГВУЗ «Приазовский государственный технический университет» г. Мариуполь, Украина; kvv.mariupol@gmail.com, ORCID:0000-0002-4863-7233

Фролов Евгений Андреевич - доктор технических наук, профессор, кафредра строительных машин и оборудования, Национальный университет «Полтавская политехника имени Юрия Кондратюка», г. Полтава, Украина; e-mail: frolov.poltntu@gmail.com; ORCID:0000-0002-2691-5386.

Ясько Станислав Георгиевич - старший преподаватель, кафедра строительных машин и оборудования, Национальный университет «Полтавская политехника имени Юрия Кондратюка», г. Полтава, Украина; e-mail: s.g.yasko@gmail.com; ORCID:0000-0001-6228-705X.

\section{About the Authors:}

Kukhar Volodymyr Valentynovych - Doctor of Technical Sciences, Professor, Head of the Department of Metal Processing Pryazovskyi State Technical University, Mariupol, Ukraine; kvv.mariupol@gmail.com ORCID:0000-0002-4863-7233

Frolov Evgeniy Andreevych - Doctor of Technical Sciences, Professor, Department of Construction Machinery and Equipment National University «Yuri Kondratyuk Poltava Polytechnic»,Poltava, Ukraine; e-mail: frolov.poltntu@gmail.com; ORCID:0000-0002-2691-5386.

Yasko Stanislav Georhyevych - postgraduate National University "Yuri Kondratyuk Poltava Polytechnic», Poltava, Ukraine; e-mail: s.g.yasko@gmail.com; ORCID:0000-0001-6228-705X. 